\title{
Psychological Well-Being, Gender and Optimistic Attitude among College Students
}

\author{
Vinayak M. Honmore $^{1}$, M. G. Jadhav ${ }^{2}$
}

\section{ABSTRACT}

The present paper aimed to study psychological well-being in relation to gender and optimistic attitude among college students. Two hundred first year Arts, Commerce and Science students (100 males and 100 females) from different colleges in Islampur and Sangli (Maharashtra) participated in the present study. The participants received Psychological Well-Being Scale (PWB) with five subscales (Sisodia and Choudhary, 2012) and Optimistic-Pessimistic Attitude Scale (Parashar, 1998). The multivariate and univariate analyses were directed to assess the subscale consistency of the PWB, the factor structure of the PWB in terms of its subscales, and gender differences in PWB, its subscales and optimistic attitude. The relationship between psychological well-being, its subscales and optimistic attitude has been thoroughly analyzed. The obtained results are discussed in the light of earlier work.

Keywords: Psychological well-being, Gender, Optimistic attitude

In the recent past, a large number of psychologists have been interested in overlapping areas like quality of life, life satisfaction, happiness, subjective well-being, psychological well-being etc. The focused efforts in these areas were partly responsible for the emergence of positive psychology. The psychologists also studied various demographic and personality correlates of the constructs just mentioned. Carol Ryff (Ryff, 1989, 1995) popularized the concept of psychological well-being and developed the necessary tools for this purpose. Ryff's Psychological well-being scale assesses six theory-guided dimensions of well-being - Positive relations with others, Autonomy, Environmental mastery, Personal growth, Purpose in life, and Self-acceptance.

Ryff (1989) reported significant overall gender difference in the Psychological well-being subscales, apparently using MANOVA. But subscalewise univariate analyses revealed gender difference only for the Positive relations with others, females scoring higher than males. Ryff (1995) replicated this finding. Roothman, Kirsten and Wissing (2003) used 13 scales related to Psychological well-being and reported small to medium gender differences on some of the

\footnotetext{
${ }^{1}$ Department of Psychology, Smt. Mathubai Garware Kanya Mahavidyalaya, Sangli

${ }^{2}$ Department of Psychology, K. B. P. College, Urun-Islampur. (Dist: Sangli)

(C) 2015 I V Honmore, M Jadhav; licensee IJIP. This is an Open Access Research distributed under the terms of the Creative Commons Attribution License (http://creativecommons.org/licenses/by/2.0), which permits unrestricted use, distribution, and reproduction in any Medium, provided the original work is properly cited.
} 
scales. In Indian context, Hasnain, Wazid and Hasan (2014) and Vijayshri (2015) found gender difference on life satisfaction, females scoring higher than men. Akhter (2015) reported females to be higher on psychological well-being. In fact, this review would be considerably lengthened if the literature on gender differences in related areas like quality of life, happiness, subjective well-being etc. is included. To sum up, in general the studies indicate either the absence of gender differences or only small to medium gender differences in psychological well-being. One aim of the present study is to explore gender differences in psychological well-being by employing a tool having the dimensions of well-being which are somewhat different from Ryff's dimensions.

One of the important attitudinal dispositions related to psychological well-being is the optimistic/pessimistic attitude. The studies by R. Singh and Dhyani (2013), S. Singh and Mishra (2014), and Hasnain, Wazid, and Hasan (2014) found no significant gender differences on optimism/pessimism. However, Naresh Kumar (2012) found females to be more optimistic, whereas Vijayshri (2015) found females to be more pessimists. Thus the findings on gender difference in optimistic/pessimistic attitudes are a bit inconsistent.

The studies relating optimism/pessimism with well-being yielded comparatively a clear picture. There is substantial evidence that optimists use different coping strategies than do pessimists and that these coping differences contribute to the positive association between optimism, better adjustment and well being. (Stanton \& Snider, 1993; Carver, Scheier, \& Weintraub, 1989). Optimists possess more extensive and supportive social networks, and report longer friendship than do pessimists; the social networks influence psychological wellbeing by operating as a stress buffer (Cohen \& Wills, 1985). Coulter's (1999) review, covering medical field, also indicates the association between pessimism and distress, and optimism and well-being. (Ferguson \& Goodwin, 2010) also found optimism to be a predictor of both subjective and psychological well-being. Thus psychological well-being and optimistic attitude appear to be positively associated.

\section{OBJECTIVES}

The objectives of the present study are as following.

1. To explore the gender differences in psychological well-being and optimistic attitude, since the earlier finding in this regard are a bit inconsistent.

2. To study the relationship between psychological well-being and optimistic attitude.

\section{HYPOTHESIS}

Psychological well-being and optimistic attitude would be positively associated. 


\section{METHOD}

\section{Participants}

Initially, 206 students (100 males and 106 females) from different senior colleges of Islampur and Sangli city (Maharashtra), studying in the first year of Arts, Commerce and Science, participated in the present study. As explained in sec. 1 of the Results, in order to have equal number of males and females, six female cases were randomly eliminated. Thus 100 males (mean age $=18.77, \mathrm{SD}=0.80)$ and 100 females (mean age $=18.43, \mathrm{SD}=0.59)$ were retained for final analysis. For the entire sample, the mean age was 18.60 years with SD of 0.72 .

\section{Tools}

1. PSYCHOLOGICAL WELL-BEING SCALE

Psychological Well-Being Scale developed by Sisodia and Choudhary (2012) was used to measure psychological well-being among the participants. It contains 50 items measuring five dimensions (subscales) of well being i.e. Life satisfaction, Efficiency, Sociability, Mental health, and Interpersonal relations. Each subscale has 10 items, each item with the five-point response category ranging from strongly agree to strongly disagree. Thus the scale provides scores on five dimensions/subscales, in addition to a score on the total psychological well-being. High score indicates high psychological well-being. For the total well-being score, the internal consistency reliability coefficient is reported to be .90 and the test-retest reliability is reported to be .87 for the normative sample. The test manual claims face and high content validity.

\section{OPTIMISTIC-PESSIMISTIC ATTITUDE SCALE}

The scale constructed by Parashar (1998) was used to measure optimistic-pessimistic attitude among the participants. It contains 40 items in which 20 items are related to optimistic attitude and 20 items are related to pessimistic attitude. Each item has two alternatives, i.e. agree and disagree, and the respondent is asked to choose one of the two alternatives. For scoring on optimistic items, ' 1 ' (one) score is given for every 'agree' response and a ' 0 ' (zero) for 'disagree' response. The scoring on pessimistic items is done in a reverse order. Thus, two separate scores, one on optimistic and the other on pessimistic attitude are obtained and the total score is obtained by adding these two scores. Higher score on this scale indicates higher optimistic attitude. The scale was developed on a sample with an age range of 13 to 25 years. The Kuder-Richardson reliability of .62 and test retest reliability of .74, with a time interval of two months is reported. The test manual reports some validity data.

\section{Procedure}

Both the scales were administered to the participants at their respective colleges with prior permission of the Principals in a small group of 10 to 15 participants at a time. The students who voluntarily agreed to participate were used in the study. 


\section{RESULTS}

\section{Data Screening and Detection of Outliers}

To begin with, the data of 206 cases (100 males and 106 females) were available. Each subject had scores on five subscales of Psychological well-being, Total psychological well-being and Optimistic attitude. The data were carefully searched for univariate outliers using a cut-off criterion of $\mathrm{z}= \pm 3.29, \mathrm{p} \leq .001$ (Field, 2005) and multivariate outliers using Mahalanobis distance $\left(\mathrm{D}^{2}\right)$, with a cut-off criterion of $\mathrm{p} \leq .001$, separately for males and females as well as for the entire sample. (While computing $\mathrm{D}^{2}$, Total psychological well-being was omitted, since its inclusion would lead to the problems related to multicollinearity and singularity.) This search identified four outlying observations. Since it was felt that these four outlying observations belonged to the population of interest, each outlying case was assigned "a raw score on the offending variable(s) that is one unit larger (or smaller) than the next most extreme score in the distribution" (Tabachnick \& Fidell, 1989, p. 70). This strategy retains the outlying cases permitting wider generalizability, but reduces their undue influence.

In order to have equal number of males and females, six cases were randomly omitted. The second search for outliers was repeated and no outliers were detected at this stage except one borderline observation which was ignored (Meyers, Gamst, \& Guarino 2006). Thus for final analysis, 200 cases (100 males and 100 females) were retained.

\section{Descriptive Statistics}

The means and standard deviations (SD) for the variables in the study are presented in Table 1 . These results will be referred to subsequently, wherever necessary

\section{Table 1: Descriptive Statistics for Psychological Well-Being and Optimistic Attitude along with} relevant univariate inferential statistics.

\begin{tabular}{|l|l|l|l|l|l|l|l|}
\hline \multirow{2}{*}{ Variable } & \multicolumn{2}{l}{ Entire sample } & \multicolumn{2}{l|}{ Male } & \multicolumn{2}{l|}{ Female } \\
& Mean & SD & Mean & SD & Mean & SD & \\
\hline Life satisfaction & 37.41 & 6.01 & 36.65 & 5.92 & 38.17 & 6.03 & 1.80 \\
\hline Efficiency & 40.34 & 4.97 & 41.00 & 4.61 & 39.68 & 5.24 & 1.89 \\
\hline Sociability & 39.42 & 5.02 & 39.41 & 5.24 & 39.43 & 4.81 & 0.03 \\
\hline Mental health & 35.43 & 6.38 & 36.61 & 6.01 & 34.25 & 6.56 & $2.65^{* *}$ \\
\hline Interpersonal relations & 42.75 & 4.46 & 42.23 & 4.89 & 43.28 & 3.93 & 1.67 \\
\hline Total PWB & 195.36 & 19.83 & 195.90 & 20.55 & 194.81 & 19.16 & 0.39 \\
\hline Optimistic attitude & 30.99 & 3.16 & 30.75 & 3.66 & 31.23 & 2.57 & 1.07 \\
\hline
\end{tabular}

$$
\text { ** } \mathrm{p}<.01 \text {.@ df=198. }
$$




\section{Gender Differences in Psychological Well-Being: Results of MANOVA and Subsequent Univariate Analyses.}

To assess the gender differences in Psychological Well-Being subscales, one-way multivariate analysis of variance (MANOVA) has been employed with gender as the independent variable and the five psychological well-being subscales as the dependent variables. To assess the suitability of MANOVA in this analysis, the pooled within-cells correlation matrix was computed among the dependent variables. The application of the Bartlett's test of sphericity to the pooled within-cells correlation matrix (Norusis/SPSS Inc, 1990) yielded the test statistic of 283.95 ( $\mathrm{df}=10, \mathrm{p}<.001$ ) indicating that the obtained within-cells correlation matrix significantly departed from the identity matrix, thus justifying the application of MANOVA instead of only multiple univariate t tests separately for each dependent variable.

The examination of residuals through the normal probability and detrended normal probability plots of the residuals for each dependent variable (Norušis/SPSS Inc, 1990) revealed that the assumption of normality did not pose a problem for the application of the MANOVA. The application of the Box's M test to the variance-covariance matrices of the concerned groups indicated that the assumption of the homogeneity of the variance-covariance matrices is satisfied $\left(\mathrm{M}=21.65 ; \chi^{2}=21.07, \mathrm{df}=15 ; \mathrm{p}>.05\right)$. No problems were detected related to multicollinearity. Thus the assumptions underlying the MANOVA are met quite satisfactorily in the present analysis, thus justifying the presentation of the MANOVA results.

The MANOVA yielded Wilks' $\Lambda$ (lambda) of $.859(\mathrm{~F}=6.39$, hypothesis $\mathrm{df}=5$, error $\mathrm{df}=194, \mathrm{p}$ $\left.<.001 ; \eta^{2}=.141\right)$. Thus the gender differences are significant at .001 level. The multivariate $\eta^{2}$ of .141 suggests that gender explained 14.1 percent variance in the corresponding canonical variate. The Life satisfaction, Efficiency, Sociability, Metal health and Interpersonal relations correlated .32, -.33, .005, -.47 and .29 respectively with the canonical variate best discriminating the two genders.

Since Wilks' $\Lambda$ is significant, the results of multiple univariate $t$ tests are also reported in Table 1 itself for space reasons. It may be noted that males scored significantly higher on the Mental health dimension of psychological well-being (males' mean $=36.61$, females' mean $=34.25, \mathrm{t}=$ 2.65, $\mathrm{df}=198, \mathrm{p}<.01$ ). Cohen's $\mathrm{d}$, the measure of effect size, turned out to be 0.38 ('small' according to Cohen, 1992). The point biserial correlation between gender and mental health dimension of psychological well-being was found to be -.19, $\mathrm{p}<.01$, suggesting that higher mental health well-being is associated with males. Gender explained 3.42 percent of variance in mental health dimension. Since the $t$ values for other subscales are non-significant, the effect sizes and relevant statistics need not be computed for them. Also the gender difference for total psychological well-being is non-significant $(\mathrm{t}=0.39$, $\mathrm{df}=198, \mathrm{p}>.05)$.

Since the variance-covariance matrices for males and females are homogenous and the mean differences across the genders are also either non-significant or small, male and female data were 
pooled together for Psychological well-being subscales for the purpose of correlational and factor analysis.

\section{Subscale Consistency and Factor Analysis of Psychological Well-Being Subscales}

To find out whether the five subscales of Psychological Well-Being are internally consistent, subscale consistency, called as 'subtest consistency' (consistency among subtests) by Cronbach (1951, p. 321), alpha coefficient was employed. Lord and Novick (1968) have also discussed the use of alpha for the reliability of composite measurements. The subscale consistency for the Psychological Well-Being Scale turned out to be .784. Armor's (1974) theta coefficient, assessing the subscale consistency, turned out to be .793. As theoretically expected, Armor's theta is slightly above the Cronbach's alpha. These are quite satisfactory values, in view of the fact that they are based on only five subscales. (While computing the subscale or subtest consistency, each subscale score is treated like an item score.) This justifies the use of total psychological well-being as a single construct.

To validate the point in the above paragraph, factor analysis of the five subscales was carried out. Table 2 reports the intercorrelations among the five subscales of the Psychological wellbeing. All the intercorrelations among the five subscales are significant at .001 level. For space reasons, this table also includes the correlations of five subscales of Psychological well-being with Optimistic attitude.

Table 2: Intercorrelations among Five Subscales of the Psychological Well-Being and Optimistic Attitude

\begin{tabular}{|l|l|l|l|l|l|l|l|}
\hline Variables & $\begin{array}{l}\text { Life } \\
\text { satisfaction }\end{array}$ & Efficiency & Sociability & $\begin{array}{l}\text { Metal } \\
\text { health }\end{array}$ & $\begin{array}{l}\text { Interpersonal } \\
\text { relations }\end{array}$ & $\begin{array}{l}\text { Total } \\
\text { PWB }\end{array}$ & $\begin{array}{l}\text { Optimistic } \\
\text { Attitude }\end{array}$ \\
\hline $\begin{array}{l}\text { Life } \\
\text { satisfaction }\end{array}$ & 1.00 & & & & & \\
\hline Efficiency & $.54^{* * *}$ & 1.00 & & & & & \\
\hline Sociability & $.35^{* * *}$ & $.40^{* * *}$ & 1.00 & & & & \\
\hline Mental health & $.42^{* * *}$ & $.51^{* * *}$ & $.38^{* * *}$ & 1.00 & & & \\
\hline $\begin{array}{l}\text { Interpersonal } \\
\text { relations }\end{array}$ & $.41^{* * *}$ & $.50^{* * *}$ & $.50^{* * *}$ & $.32^{* * *}$ & 1.00 & & \\
\hline $\begin{array}{l}\text { Optimistic } \\
\text { Attitude }\end{array}$ & .04 & $.21^{* *}$ & .08 & .08 & $.20^{* *}$ & $.16^{*}$ & 1.00 \\
\hline
\end{tabular}

The suitability of the $5 \times 5$ correlation matrix (representing the intercorrelations among the five subscales of the PWB) for factor analysis was assessed by visual scrutiny. The application of Bartlett's test of sphericity yielded the test statistics, $\chi^{2}=271.80, \mathrm{df}=10, \mathrm{p}<.001$, suggesting that the obtained correlation matrix significantly departed from the identity matrix. The overall KMO index is .80 which can be classified as 'meritorious' (Kaiser, 1974). The KMO indices for 
Life satisfaction, Sociability and Mental health are $.83, .80$ and .81 respectively, all three of them being 'meritorious'. The KMO indices for Efficiency and Interpersonal relations are .77 and .78 respectively, both of them being 'middling'. This pre-factor-analysis examination testified the factorability of the correlation matrix.

In the initial run, both eigenvalue $\geq 1$ criterion and Cattell's scree plot, presented in Figure 1, suggested a single factor solution. As the initial run indicated, the first principal component condensed 54.72 percent of variance. However, with the limited number of variables (five in this analysis), common factor model is better suited than the component model. As such, the results of principal axis factoring (common factor model) are only reported in Table 3. With single factor solution, further rotation is not necessary. KMO indices are also presented in this Table to save space.

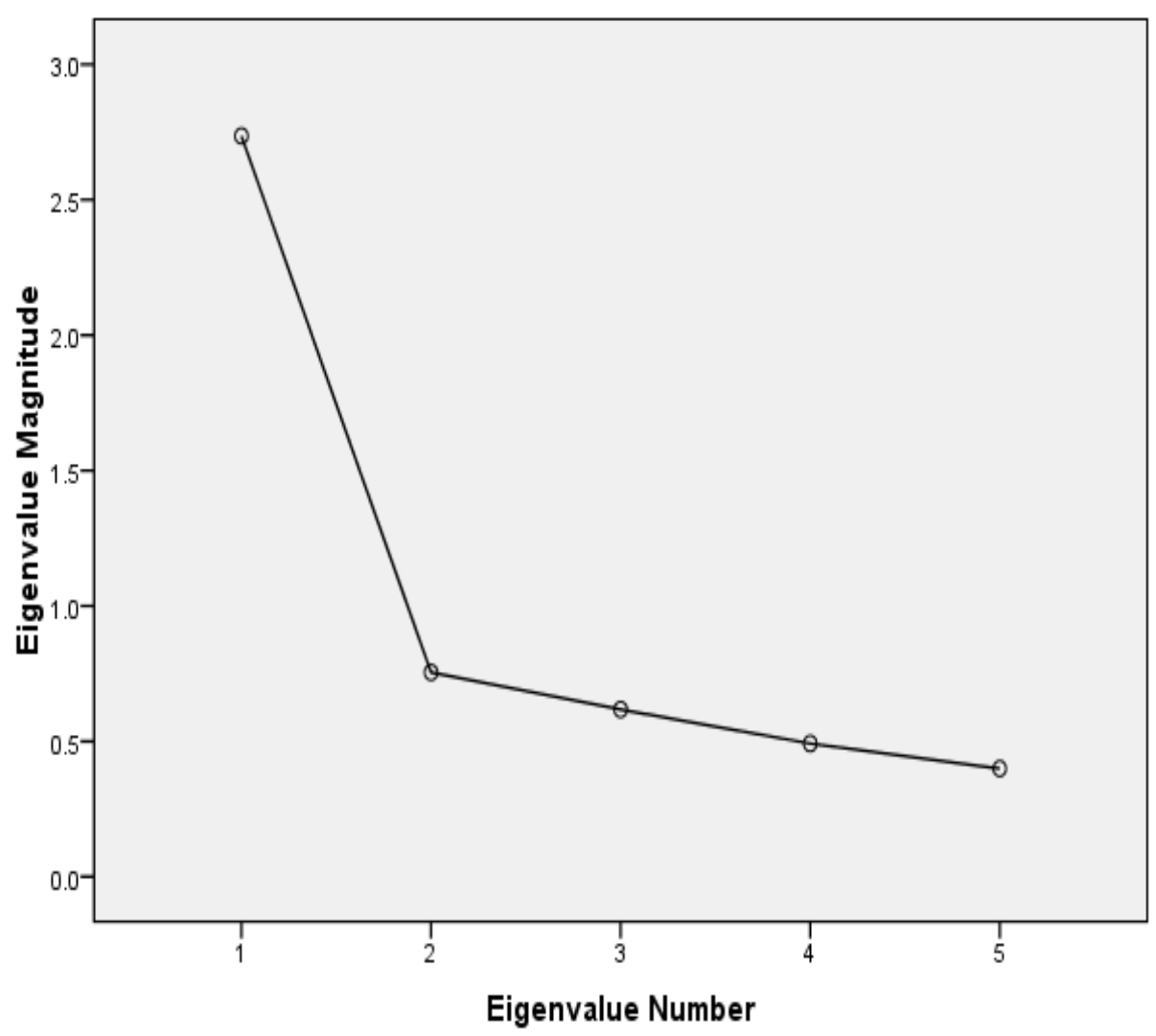

Figure 1: Cattell's Scree Plot for the Five Subscales of Psychological Well-being Scale 
Table 3: Factor Analysis of Psychological Well-Being Subscales.

\begin{tabular}{|l|l|l|l|}
\hline \multirow{2}{*}{ Well-being Subscales } & \multicolumn{2}{l|}{ First Principal Axis Factor } & \multirow{2}{*}{ KMO Indices } \\
\cline { 2 - 4 } & Loadings & $\mathbf{h}^{2}$ & \\
\hline Life satisfaction & .66 & .433 & .83 \\
\hline Efficiency & .77 & .595 & .77 \\
\hline Sociability & .60 & .361 & .80 \\
\hline Mental health & .61 & .371 & .81 \\
\hline Interpersonal relations & .65 & .425 & .78 \\
\hline Total Variance explained & & 43.70 percent & Over all KMO $=.80$ \\
\hline
\end{tabular}

* For space reasons, KMO indices are also presented in this table.

The examination of Table 3 indicates that all the factor loadings are sufficiently high. The first principal axis factor condensed 43.70 percent of variance. The first principal axis factor score (obtained by regression method) correlated .989 with the Total psychological well-being score. Thus, the single-factor solution is accepted.

\section{Psychological Well-Being in relation to Gender and Optimistic Attitude}

The application of the $t$ test indicated non-significant gender difference in Optimistic attitude $(\mathrm{t}=$ 1.07, $\mathrm{df}=198, \mathrm{p}>.05$ ). Table 2 indicates that the Optimistic attitude correlated positively with the total Psychological well-being $(\mathrm{r}=.16, \mathrm{p}<.05)$. The first principal axis factor score of the PWB correlated $.18(\mathrm{p}<.01)$ with the Optimistic attitude. However, the Optimistic attitude correlated significantly, and of course positively, only with the two subscales of Psychological well-being - Efficiency $(r=.21, p<.01)$ and Interpersonal relationships $(r=.20, p<.01)$. Thus the results partially support the hypothesis stating that 'Psychological well-being and optimistic attitude would be positively associated'.

The pooling of male and female data of the five subscales for their correlational and factor analysis has already been justified above. However, in the context of Optimistic attitude, the preliminary scrutiny suggested that the correlation of Optimistic attitude with Sociability subscale is different for males $(r=.25, \mathrm{p}<.05)$ and females $(r=-.19 \mathrm{p}=.065$, quite close to .05 level of significance). The application of $\mathrm{z}$ test to evaluate difference in two independent correlations revealed that the correlations between Sociability and Optimistic attitude significantly differed in males and females $(\mathrm{z}=3.06, \mathrm{p}<.01)$. This resulted in the nonsignificant correlation $(r=.08$ ) between Optimistic attitude and Sociability for the entire sample. The correlations of Optimistic attitude with other subscales and Total psychological well-being showed no gender difference as per the $\mathrm{z}$ tests. Thus gender moderates only the relationship between Optimistic attitude and the Sociability dimension of Psychological well-being. Hence, in the context of relationship between Optimistic attitude with Psychological well-being subscales/scale, except for Sociability, the correlation values for the entire sample would be more appropriate and the same have been used while evaluating the hypothesis. The application 
of canonical redundancy analysis revealed that Gender and Optimistic attitude together explained 10.6 percent of variance in the five subscales of Psychological well-being.

\section{DISCUSSION}

The results (sec. 4) indicate that the subscale consistency for the Psychological well-being scale, used in the present study, is quite satisfactory. The factor analysis of the five subscales of the PWB yielded a single factor solution, explaining 43.70 percent of variance. This is quite a satisfactory percent of variance explained, especially in view of the fact the common factor model has been followed. Thus, in the context of the present PWB scale, it is possible to conceptualize total, overall or general psychological well-being as a single construct. Panicker (personal communication, August, 2015) carried out a similar analysis for Ryff's PWB scale and similar results have been obtained.

The MANOVA results (sec. 3) indicate the significant overall gender difference. This result is similar to Ryff's (1989, p. 1076) finding about the 'overall effect of sex' on psychological wellbeing, though Ryff's scale and the PWB scale in the present study employed different dimensions or subscales. The results also indicated that the psychological well-being in terms of Mental Health dimension is better in males than females, although the effect size in this context is small (Cohen's $d=.38$ ). The majority of the participants in this study belonged to rural or semi-urban background characterized by male dominance and emphasis on traditional norms and restrictions on females. In a society in transition, this may create some mental health problems for the college going females where equality of the genders is emphasized at conceptual level. Thus the present findings are in line with the earlier evaluation of the literature on gender differences in introduction indicating 'either the absence of gender differences or only small to medium gender differences'.

The results (sec. 5) also indicated the absence of gender difference in optimistic attitude. This finding is in agreement with the results of R. Singh and Dhyani (2013), S. Singh and Mishra (2014), and Hasnain, Wazid, and Hasan (2014). The results also indicated that the optimistic attitude correlated with Total psychological well-being $(r=.16, \mathrm{p}<.05)$ as well as the first principal axis factor of the psychological well-being $(r=.18, p<.01)$. Although these two correlations are statistically significant and support the hypothesis, they are comparatively 'small' using Hopkins' categorization (cited in Kotrlik and Williams, 2003).

The present work has yielded some interesting results. In the subscalewise analysis, Optimistic attitude significantly correlated with only the two subscales - Efficiency and Interpersonal relations- of the Psychological well-being scale employed in the present work. Thus while exploring the relationship between personality characteristics, including optimistic attitude, and psychological well-being, subscalewise analysis appears to be more informative. In the present research, gender moderated the relationship between Sociability dimension of the psychological well-being and optimistic attitude. From the cross-cultural perspective, this is an interesting finding and needs to be further explored. 
Author Note/Acknowledgement: V. M. Honmore (hvinayak30@gmail.com) is currently working as an Assistant Professor, Department of Psychology, Smt. M. G. Kanya Mahavidyalaya, Khan Bhag, Sangli 416 416. M. G. Jadhav, Ph. D. (drmg.jadhav@rediffmail.com) is currently working as an Associate Professor and Head, Department of Psychology, K. B. P. College, Urun-Islampur, Dist: Sangli. We gratefully acknowledge Prof. P. H. Lodhi, former Head, Department of Psychology, University of Pune, Pune 411 007, for critically reading the manuscript and for his suggestions. Reprint request and other correspondence should be addressed to the first author.

\section{REFERENCES}

Akhter, S. (2015). Psychological well-being in student of gender difference. The International Journal of Indian Psychology, 2 (4).

Armor, D. J. (1974). Theta reliability and factor scaling. In H. L. Costner (Ed.), Sociological Methodology (pp. 17-50). San Francisco: Jossey-Bass.

Carver, C. S., Scheier, M. F., \& Weintraub, J. k. (1989). Assessing coping strategies: A theoretically based apporach. Journal of Personality and Social Psychology , 56 (2), 267283.

Cohen, J. (1992). A power primer. Psychological Bulletin , 112, 155-159.

Cohen, S., \& Willis, T. A. (1985). Stress, social support and the buffering hypothesis. Psychological Bulletine , 98 (2), 310-357.

Coulter, L. A. (1999). Optimism, coping and psychological well-being among people with advanced cancer. Dalhousie University, For the degree of Master of nursing, Halifax, Nova Scotia.

Cronbach, L. J. (1951). Coefficient alpha and the internal structure of tests. Psychometrika , 16, 297-334.

Ferguson, S. J., \& Goodwin, A. D. (2010). Optimism and well-being in older adults: The mediating role of social support and perceived control. The International Journal of Aging and Human Development , 71 (1), 43-68.

Field, A. P. (2005). Discovering statistics usuing SPSS . London: Sage.

Hasnain, N., Wazid, S. W., \& Hasan, Z. (2014). Optimism, hope, and happiness as correlates of psychological well-being among young adult assamese males and females. IOSR Journal of Humanities and Social Science, 19 (2), 44-51.

Kaiser, H. F. (1974). An index of factorial simplicity. Psychometrika , 39, 31-36.

Kotrlik, J. W., \& Williams, H. A. (2003). The incorporation of effect size in information technology, learning, and performance research. Information Technology, Learning, and Performance Journal , 21 (1), 1-7.

Lord, F. M., \& Novick, M. O. (1968). Statistical theories of mental test scores. Reading, MA: Addison-Wesley.

Meyers, L., Gamst, G., \& Guarino, A. (2006). Applied multivariate research: Design and interpretation. Thousands oaks: Sage. 
NareshKumar. (2012). Emotional intelligence as related to optimistic-pessimistic attitude of B. Ed. teacher trainees. International Journal of Basic and Advanced Research , 1 (3), 5356.

Parasher, D. S. (1998). The manual for optimistic-pessimistic attitude scale. Jabalpur: Asrohi Manovidnan Kendra.

Roothman, B., Kristen, D. K., \& Wissing, M. P. (2003). Gender differences in aspects of psychological well-being. South African Journal of Psychology , 33 (4), 212-218.

Ryff, C. D. (1989). Happiness is every thing, or is it? Explorations on the meaning of psychological well-being. Journal of Personality and Social Psychology , 57 (6), 10691081.

Ryff, C. D. (1995). The structure of psychological well-being. Journal of Personality and Social Psychology, 719-727.

Singh, R., \& Dhyani, A. (2013). Attitude towards life: A family environment perspective. International Conference on Social Science Research, ICSSR, (pp. 1547-1551). Penang, Malaysia.

Singh, S., \& Mishra, S. (2014). Optimism-pessimism among adolescents- A gender based study. International Journal of Science and Research (IJSR) , 3 (6), 1530-1532.

Sisodia, D. S., \& Choudhary, P. (2012). Manual for Psychological well-being scale. Agra: National Psychological Corporation.

Stanton, A., \& Snider, P. (1993). Coping with a breast cancer diagnosis: A prospective study. Health Psychology , 12 (1), 16-23.

Tabachnick, B., \& Fidell, L. S. (1989). Using multivariate statistics. New York: Harper \& Row.

Vijayashri. (2015). Life satisfaction influenced by optimistic and pessimistic attitude: A study of older adults. International Journal of Scientific Research , 4 (5), 728-731. 